\title{
Analysis on the Application of Enterprise Financial Information Analysis in the Management of Electric Power Enterprises
}

\author{
Leiping Wu \\ State Grid Yantai Power Supply Company, Yantai Dongyuan Electric Power Design Co.Ltd. \\ Shandong Yantai, China, 264001
}

Keywords: financial management, power enterprise, financial management, economic risk

Abstract: Enterprise financial information management plays an important role in the overall operation of power companies. It can predict the economic risks of power companies in advance, and can reflect the financial data under the operating status of enterprises. As the basis of financial management, financial analysis plays an important role in the business model of power companies.

\section{Introduction}

As an important power enterprise to promote economic development, power companies have achieved remarkable results in the development and management of power energy. In the current situation of power companies continuing to operate, relevant researchers found that there are some problems in the internal economic structure of power companies. The financial management of power companies is the mainstay. The financial management of power companies is not proportional to the overall development of power companies, result lacking of positive financial information support in the overall development of power companies, which will lead to cost waste in electricity companies.

\section{Analysis of Corporate Financial Information}

\subsection{Concept}

Financial information management, as the name implies, is the unified integration of the circulation data of property, as well as the financial revenue and expenditure, financial budget, including the circulation and circulation purposes involved in the financial flow process ${ }^{[1]}$. And according to the existing data, it is analyzed and classified. It is applied to enterprises, mainly to reflect the financial situation and cost losses of enterprises in the process of capital circulation. Through the investor's specific investment projects and investment amount, as well as the creditor's control over the debt cost recovery process, the government should macro-control the change process and set up corresponding management measures to set the development standards for future projects from the enterprise itself. Rational planning of financial costs based on development criteria. 


\subsection{Role}

The core strength of the enterprise is the financial-centered data statistics, the development of corporate financial information, and the supervision of the financial audit department. In order to realize informationization at an early date, the financial department of the enterprise should be improved in time, the company's business policy should be adjusted in a timely manner, and the corporate culture should be integrated into the enterprise for financial management, and the financial information should be scientifically controlled ${ }^{[2]}$. Modern financial information management through the technical software, the company's financial circulation is supervised, and in this way to achieve the clear state of the company's revenue and expenditure. On this basis, rational allocation of resources has a crucial guarantee for the advancement of the enterprise. At the same time, corporate financial information management plays a reference role in corporate customer relationship and resource allocation. In order to make the various processes of the enterprise have certain norms, there must be certain links between the various departments within the enterprise, especially with the financial department, the financial department is the economic lifeline of the enterprise, and the operation of a company can be reflected by the financial information. Intuitively, it has played a coordinating role in the overall management of the enterprise.

\subsection{Characteristics}

The management of financial information of enterprises in the power industry needs to be carried out under reasonable policies. From the perspective of the special nature of power companies, it is an indispensable industry to promote social development ${ }^{[3]}$. In terms of nature, the application of corporate financial management to power companies is relatively specific. First, power companies are energy-driven industries. The main task of work is to maintain the energy supply for people's normal work. Its resource development control and cost of production require relative rigor and are therefore subject to national policies. Second, the development of power companies is different in nature, from power generation devices to power generation applications. The equipment for power development has a fixed nature, accounting for most of the cost of power companies, from hydropower stations to distributed photovoltaic power plants, and then to wind power generation. Including the thermal power used in some areas, the power generation devices are different, resulting in different ratios of call capacity. This phenomenon affects the distribution of the amount of assets of power companies. From this perspective, the financial information management of power companies is necessary. Third, the rational application of enterprise financial information management in power companies can effectively avoid risks. From the perspective of the working status of power distribution equipment, the energy distribution of power enterprises has certain regularity, and it is subject to state control, and grid charging has certain standards. Some areas are affected by economic conditions, and there are often situations in which electricity bills cannot be paid in a timely manner. This phenomenon will lead to a loss of balance in the circulation of power grid assets and raise the risk of funds for power companies.

\subsection{Status Quo}

The management concept of China's electric power enterprises stays in the state of mind based on energy supply such as power generation and distribution. Under the influence of this kind of thinking, the development of electric enterprises ignores internal construction ${ }^{[4]}$. For a long time, internal financial management has not received much attention, and it has structural defects, especially the shortcomings of financial management methods, and failed to form a management system that best meets China's power resource allocation. Until the end of the 20th century, China introduced the 
financial software of artificial intelligence, in order to achieve a high degree of integration of financial management and information. Although the introduction of artificial intelligence has realized the initial development foundation of financial management of electric power enterprises, in the operation process in recent years, the operation of financial information has presented a large one-sidedness. For example, the financial material personnel's laziness caused the compilation of enterprise material information is not comprehensive, and the information reporting is not timely.

\section{The Analysis of Corporate Financial Information Used in Power Companies}

\subsection{Not Receiving the Attention of Relevant Personnel}

In the current situation of China's power enterprise management, it is prone to the phenomenon of heavy work tasks. Since the business nature of power companies is mainly based on the production and distribution of power resources, the product projects are relatively simple and have few profitable projects in the entire power generation activities, but relatively concentrated ${ }^{[5]}$. Affected by this phenomenon, the financial management system of electrical appliances is relatively simple. The workers in the power manufacturing industry regard the economic lifeline of enterprises as the focus of production and manufacturing, thus neglecting the work of financial information analysis of enterprises.

\subsection{Analysis is not authoritative}

In the current situation, the financial department of the electric enterprise has carried out research on the analysis of financial information, and has adopted the intelligent information-based financial software for accurate analysis. However, this analysis mode has certain drawbacks, that is, the statistical work of analyzing information is not detailed enough. Leading to the analysis process of the characters is too long, the final analysis results cannot be applied to the corresponding theory; the analysis program is not professional, resulting in the purpose of financial information analysis is not clear, the analysis process is not refined, the analysis results are not authoritative.

\subsection{There is a Phenomenon of Retention in the Level of Financial Information Analysis}

Although the use of information software to promote the efficiency of analytical work, in the current analysis work, there are cases of unreasonable staffing, including the management of manpower and the management of work efficiency are not perfect ${ }^{[6]}$. Relevant policies encourage information production, which leads to the loss of crisis awareness among corporate departments and the loss of subjective initiative.

\subsection{Problems of the Enterprise Manager Itself}

Aside from the rigid issue of financial information analysis of power companies, a force that plays a decisive role in enterprises is enterprise leaders. Leaders have the power to make decisions. The management of a company depends directly on its leadership ability. In the current situation, the management of the power company is not professional, and only focuses on the use of management power. In this case, the management decisions will be uncertain, and even loopholes and mistakes. The financial information analysis of electric enterprises requires professional knowledge, accurate observation of information, and reasonable system control and timely communication of problems. Only in this way will a complete financial management system be formed. 


\section{The Work Focus in the Analysis of Corporate Financial Information}

\subsection{Data Statistics are the Focus of Financial Information Analysis}

Financial information analysts of power companies are required to have high professionalism and a strong sense of responsibility for their work. The capacity allocation of power companies has group differences. According to the different people, the allocation of power resources will be subject to corresponding changes ${ }^{[7]}$. The financial analyst should conduct real-time data statistics on the monthly usage of electric energy and the main purpose of electric energy distribution, correctly distinguish the relationship between the electric power paths, and track the running status of the electric meter in real time. Emphasis is placed on a wide range of accurate statistics on various data of the distribution system. The statistical result is to facilitate the analysis of financial reports.

\subsection{Developing Record Habits is the Focus of Financial Analysis Work}

In the operation of power companies, there will be large data generation. From the manufacturing cost generated in the first-line work process to the quantity and distribution path of the resources allocated to the second-line work, we require relevant personnel to be sensitive to the data. Develop a habit of positive recording. On this basis, in the process of power resource manufacturing, the energy development device operation process will generate voltage data and related power load data. The data displayed by these devices directly determines the operation status of the device, and requires front-line staff to have direct judgment on the data. The financial staff should summarize the rules according to the device data within a certain period of time, and effectively avoid financial risks according to the regular presentation. It is necessary to classify major events arising from various work links in a timely manner to facilitate the analysis of financial information.

\subsection{The Comprehensive Analytical Ability of Training Posts is the Focus of Analytical Work}

The financial analysis work of electric enterprises is subject to the acquisition of basic materials and the assembly process of basic equipment. It is necessary to pay close attention to the operation process of the power system, including the distribution network work flow and the power generation details of various power generation devices, which have profound implications for the overall operation of the enterprise. Understanding, combined with the overall workflow to screen the processes that the finance department needs to work with. For example, the labor cost of the material purchase and assembly process, the financial department should properly regulate it, and improve the distribution of materials between departments according to the minutes of the meeting ${ }^{[8]}$. In summary, relevant personnel must have a global awareness of financial information analysis. Under normal circumstances, the financial analysis of the enterprise is the responsibility of the financial personnel. The department system of the electric enterprise is relatively large. The analysis of the individual departments is inevitable, which will inevitably lead to imperfect information communication between the departments. The financial information in the departmental area is statistically and simply analyzed, and finally integrated through departmental collective meetings, achieve the efficiency of analytical work. 


\section{The Specific Application of Financial Information Analysis of Power Companies}

\subsection{Analysis of Income and Expenditure Information of Simple Funds of Electric Enterprises}

The revenue and expenditure of simple funds of electric enterprises mainly include electricity and electricity sales. The main profit and loss ratio of electric enterprises has a huge relationship with the two ${ }^{[9]}$. Electricity sales are the main way for the income of electricity companies. In order to have a comprehensive control over the overall operation of the power company, a comprehensive analysis of the sales subject and sales volume of the electricity sales is required. A reasonable analysis of the factors affecting the incremental impairment of electricity sales will reduce the financial losses of the electricity companies. The sales of electric enterprises need to be promoted by sales methods, and reasonable sales methods will increase the market competitiveness of power resources. Therefore, the data is summarized and the data is analyzed effectively, and the market competitiveness of power resources can be identified in time. The object of collecting electricity charges is mainly the household electricity users, the electricity consumers of commercial enterprises, the analysis of the payment channels and payment principles of different collection agencies, and can quickly obtain the monthly or annual electricity tariff changes. In this case, some users will be in arrears, analyze the reasons for the arrears in a timely manner according to the data of the payment route, and formulate a default management system and take corresponding preventive measures.

\subsection{Analysis of the Comprehensive Factors Affecting the Finance of Electric Power Enterprises}

\subsubsection{Analysis of Profitability}

In the financial management of electric enterprises, there are three major factors, namely profit and loss, liabilities and operations. From the perspective of profit and loss, whether electric enterprises have market competitiveness requires the operation of integrated power companies to net profit and return on assets and the loss rate is analyzed and judged by comprehensive indicators. Through the main income project of the electric enterprise, the analysis of the growth law of the profit amount is carried out, and the comprehensive analysis of the total assets income of the enterprise and the net profit of the individual project is carried out.

\subsubsection{Analysis of Solvency}

The establishment of electric power enterprises requires complete construction of the power grid. The engineering system for establishing power grids is relatively large. Most enterprises will use bank loans to invest in construction projects. In the later operation process of electric power enterprises, they must regularly analyze and evaluate the repayment ability. The level of loan ability directly affects the business status of the company. The financial personnel of the electric enterprise should follow up the various circulation economy of the enterprise in a timely manner and comprehensively record the financial circulation data in order to achieve a comprehensive assessment of the ability to repay the loan.

\subsubsection{Operational Perspective}

From the operational point of view, the financial revenue and expenditure of the electric enterprise directly reflects the operational effect and operational status. The main economic source of the electric enterprise is the collection of electricity charges. The development of the electric enterprise requires regular upgrading of the production equipment. This process involves the purchase and 
maintenance cost control of the parts requires a reasonable analysis of the inventory rate and the capital turnover range before the device improvement is completed, thereby avoiding financial risks.

\section{Conclusion}

According to the above expression, the operational nature of the electric enterprise is explained, including the necessity and characteristics of the financial management of the enterprise. The application of enterprise financial information analysis in the operation and management of power companies can effectively avoid the financial risks of enterprises, and has substantial operational significance for the company's profit and loss and cost budget. Only when the financial information analysis is reasonably applied to the power enterprise can the power enterprise have good social competitiveness.

\section{References}

[1] Yulei Zhang. Application of Enterprise Financial Information Analysis in Power Enterprise Management [J]. China Electric Power Education, 2008(24):203-204.

[2] Wei Zhu. Exploring the Application of Financial Information Analysis in the Management of County-level Power Companies [J]. Technology Economic Market, 2015 (1): 61-61.

[3] Juan Xu, Ping Zhang, Jing Zhang, et al. Application of Financial Information Analysis in Enterprise Management of Electric Power Enterprises [J]. Building Materials and Decoration, 2017(25).

[4] Huidong Bo. Current Situation and Common Problems of Financial Management Informationization in Power Enterprises [J]. Corporate Herald, 2013(10): 119-120.

[5] Xiaofei Xin. Analysis on the Path of Strengthening Financial Management of China's Power Enterprises [J]. Financial sector, 2010(12):200-200.

[6] Lei Huang. Application of Project Management Theory in Financial Intensive Management of County-level Power Supply Enterprises [J]. Modern Economic Information, 2014(4): 174-174.

[7] Dongjuan Yan, Hui Fang. Application of Project Management Theory in Financial Intensive Management of County-level Power Supply Enterprises [J]. Finance and Economics: Academic Edition, 2016(22).

[8] Mingjun Ding. Application of Information Technology in Financial Management of Power Companies [J]. Economy: 00217-00217.

[9] Qian Wang, Yanhong Zhu, Zhengdong Wang, et al. The use of Information Technology in Financial Management of Power Companies [J]. Finance and Economics (Academic Edition), 2015 (7): 216-216. 